\title{
POLÍTICA MIGRATORIA: ENTRE EL DISCURSO, LA PRÁCTICA Y LA COYUNTURA
}

\author{
IMMIGRATION POLICY: BETWEEN DISCOURSE, \\ PRACTICE AND REALITY
}

\section{LA POLITIQUE MIGRATOIRE MEXICAINE: LE DISCOURS, LA PRATIQUE ET LA CONJONCTURE}

\author{
Jorge Durand ArP-Nisen \\ Universidad de Guadalajara - Centro de \\ Investigación y Docencia Económicas, CIDE \\ j.durand.mmp@gmail.com
}

Resumen: En este texto evaluaremos los planteamientos generales de la política migratoria durante el sexenio del presidente Enrique Peña Nieto, plasmados en el Programa Especial de Migración, y en la manera en que éste fue operado en la práctica por los funcionarios encargados. Finalmente, se analizarán los casos coyunturales más representativos: la creación del Plan Frontera Sur ante la crisis humanitaria de niños y familias migrantes, el desvío de fondos del IME a Juntos Podemos y las caravanas hondureñas de fin de sexenio.

Palabras clave: migración; política migratoria; IME; caravana migrante; frontera sur; Enrique Peña Nieto.

AвSTRACT: In this text we will evaluate the general approaches taken by migration policy during the presidency of President Enrique Peña Nieto, as embodied in the Special Migration Program, and in the manner in which it was put into practice by the officials in charge. Finally, the most representative cases will be analyzed: the creation of the Southern Border Plan in response to the humanitarian crisis of migrant children and families, the diversion of funds from the IME to Juntos Podemos, and the Honduran caravans at the end of the six-year period.

Keywords: migration; immigration policy; IME; migrant caravan; southern border; Enrique Peña Nieto.

Traducción de GonZalo Celorio Morayta 
RésumÉ: Ce texte évalue les propositions de politique migratoire le long de la période présidentielle d'Enrique Peña Nieto, telles qu'elles figuraient sur le Programme spécial pour la migration, dont la mise en pratique est un autre sujet d'analyse. On examine les choix les plus significatifs de cette politique: l'adoption du Plan pour la frontière Nord, visant surtout les enfants, lors de la crise humanitaire des familles de migrants; le détournement de fonds du budget de l'Institut des Mexicains de l'Étranger (IME) au profit du programme d'appui Juntos Podemos; et, à la fin de cette période, les caravanes provenant du Honduras.

Mots clefs: politique migratoire; IME; caravanes de migrants; frontière Sud; Enrique Peña Nieto.

Traducción de Bernardo Mabire

Fecha de recepción: diciembre de 2018

Fecha de aceptación: febrero de 2019 
$\mathrm{L}$

A política migratoria mexicana de las dos primeras décadas del siglo xxi presenta matices y contrastes en las tres administraciones recientes. Durante el sexenio de Vicente Fox (2000-2006) se definió una política proactiva y a favor de lograr un acuerdo migratorio con Estados Unidos, hasta los sucesos del 11 de septiembre de $2001 .^{1}$

El sexenio de Felipe Calderón se distinguió por una política que se fue al otro extremo y pretendía "desmigratizar" la relación bilateral y enfocarse en la guerra contra el narcotráfico, con énfasis en la Iniciativa Mérida, aunque hay que reconocer que concluyó con la promulgación de la Ley de Migración de 2011, propiamente de extranjería, que fue un avance parcial importante. ${ }^{2}$

Por otra parte, el sexenio de Enrique Peña Nieto hereda la Ley de Migración y su reglamento y retoma la propuesta de incluir en el Plan Nacional de Desarrollo un apartado especial llamado Programa Especial de Migración (PEM), logrado en consenso con diversas organizaciones de la sociedad civil. Se trata propiamente de una política de Estado con respecto a la migración, a cargo de la Secretaría de Gobernación, en coordinación con otras secretarías.

En ese contexto, de amplia participación de la sociedad civil en el Programa Especial de Migración, paradójicamente se trató de aplicar una "política sin estridencias" en la relación bilateral, en la que el tema migratorio se mantenía en un perfil bajo, incluso durante las discusiones sobre reforma migratoria sostenidas en el propio Senado estadounidense (2013). Pero la cruda realidad forzó una reacción, durante la crisis de niños y familias migrantes centroamericanas en 2014, con la creación del Plan Frontera Sur; a ello, se suman los ataques y exabruptos de Donald Trump durante su campaña electoral y en los primeros años de su mandato y, finalmente,

${ }^{1}$ Jorge G. Castañeda, Ex mex: From migrants to immigrants, Nueva York/ Londres, The New Press, 2009.

2 Jorge Durand, "La «desmigratización» de la relación bilateral: balance del sexenio de Felipe Calderón, Foro Internacional, 53 (2013), pp. $750-770$. 
la crisis de las caravanas y el éxodo de migrantes hondureños de fines de sexenio.

Sin duda fue un sexenio movido y conflictivo en el campo migratorio, pero en política exterior se mantuvo la ecuanimidad, incluso en momentos álgidos, sin que se perdiera la compostura. Más bien, las estridencias llegaron del vecino del norte, en forma de ataques sistemáticos a las personas migrantes, de la pretensión de construir un muro fronterizo a toda costa -mejor dicho, a costa de los mexicanos- y de la utilización permanente del tema migratorio como política central y hegemónica de la campaña electoral por la presidencia estadounidense, así como en los comicios intermedios.

De igual modo, la turbulencia llegó del exterior, con tres caravanas de migrantes en 2018 (caravana Viacrucis del Migrante, caravana de madres de migrantes desaparecidos y caravana hondureña o éxodo centroamericano) que pusieron en jaque al gobierno federal, a los estados por donde transitaban y a las ciudades en las que pernoctaban, hasta que llegaron a Tijuana y la frontera con Estados Unidos.

Otros hitos importantes fueron la derivación de gran parte del presupuesto del Instituto de Mexicanos en el Exterior (IME) a la institución privada Juntos Podemos, lo que significó un importante cambio en un programa que había sido relevante en los sexenios anteriores como vínculo y promotor de la comunidad mexicana radicada en Estados Unidos; la participación de la Secretaría de Relaciones Exteriores (SRE), en convenio con el Instituto Nacional Electoral (INE), en el programa de "credencialización" de mexicanos en el exterior con vistas a las elecciones de 2018; la participación de México como anfitrión y deliberante en el Pacto Global de Migración y, finalmente, el manejo político y los entretelones de las caravanas migrantes de hondureños de 2018, su impacto mediático y las relaciones multilaterales.

En este texto evaluaremos los planteamientos generales de la política migratoria durante el sexenio del presidente Enrique Peña Nieto, luego se hará un repaso a la manera en que 
fue operada en la práctica y, finalmente, analizaremos los casos coyunturales más representativos.

\section{UNA POLÍTICA DE ESTADO PARA LA MIGRACIÓN}

La Ley de Migración de $2011^{3}$ generó una amplia discusión entre diversos grupos de académicos, políticos, defensores de los derechos humanos y organizaciones de la sociedad civil. El tema migratorio había sido puesto sobre la mesa, a pesar de que dicha ley propiamente se refiera a asuntos de extranjería, dejando de lado la emigración y el retorno. El debate prosiguió durante la elaboración de su reglamento, en la que también hubo diálogo y participación.

En ese contexto, varias organizaciones, entre ellas el Colectivo Migraciones para las Américas (COMPA), propusieron que el tema migratorio formara parte del Plan Nacional de Desarrollo (PND) de la administración de Enrique Peña Nieto (2012-2018). Para ello, se organizaron diversos foros, consultas y talleres que concluyeron con la elaboración de un documento.

Posteriormente, el 30 de abril de 2014, se publicó en el Diario Oficial de la Federación el Programa Especial de Migración, que considera a México como "país de origen, tránsito y destino y retorno de migrantes" y propone un plan "integral" ligado al PND, de observancia obligatoria. El documento parte de los convenios y acuerdos internacionales firmados por México y establece que "una política migratoria de Estado tiene por objeto superior el bienestar del migrante, a

${ }^{3}$ Decreto por el que se expide la Ley de Migración y se reforman, derogan y adicionan diversas disposiciones de la Ley General de Población, del Código Penal Federal, del Código Federal de Procedimientos Penales, de la Ley Federal contra la Delincuencia Organizada, de la Ley de la Policía Federal, de la Ley de Asociaciones Religiosas y Culto Público, de la Ley de Inversión Extranjera, y de la Ley General de Turismo, Diario Oficial de la Federación, 25 de mayo de 2011, http:/ /www.diputados.gob. $\mathrm{mx} /$ LeyesBiblio/ref/lmigra/LMigra_orig_25may11.pdf 
través del ejercicio efectivo de su identidad, del disfrute de sus derechos sociales, económicos y culturales. Busca hacer efectivo su bienestar para consolidar su papel como agente para el desarrollo". 4

$\mathrm{Al}$ mismo tiempo, se hace un reconocimiento al origen consensuado de esta propuesta:

la política migratoria mexicana tiende a la gobernanza de las migraciones, es decir, hacia un esquema de tipo relacional que se basa en la interlocución coordinada entre los diversos actores involucrados (públicos, privados, organizados, no organizados, individuales o colectivos). Esto no sólo con el propósito de fortalecer la atención integral del fenómeno en un ambiente de responsabilidad nacional e internacional, sino también con el fin de garantizar el debido respeto a los derechos humanos de las personas migrantes. ${ }^{5}$

Por otra parte, el documento considera que es indispensable un "cambio en el paradigma gubernamental sobre el fenómeno migratorio”, por lo que la política migratoria debe ser integral, de largo plazo, corresponsable, garante del respeto de los derechos de los migrantes, orientada al desarrollo de la comunidad y al bienestar del migrante, intergeneracional, con perspectiva de género y de seguridad humana de tipo participativo y coordinado interinstitucionalmente. 6

El programa se plantea cinco objetivos, de acuerdo con los cuatro tipos de flujos migratorios que considera, y cada uno de ellos se desglosa en estrategias y líneas de acción. El primero es "impulsar las relaciones bilaterales que contribuyan a ampliar la presencia de México en el mundo”, para lo

${ }^{4}$ Programa Especial de Migración, Diario Oficial de la Federación, 30 de abril de 2104, http:/ / www.dof.gob.mx/nota_detalle.php?codigo=534307 $4 \&$ fecha $=30 / 04 / 2014$.
${ }^{5}$ Loc. cit.
${ }^{6}$ Loc. cit. 
cual es necesario "fomentar una cultura de la legalidad, de derechos humanos y de la valoración de la migración". ${ }^{7}$

En segundo término, se propone "fortalecer la participación social para impulsar el desarrollo comunitario a través de esquemas de inclusión productiva y cohesión social”, con la meta de "incorporar el tema migratorio en las estrategias de desarrollo regional y local". 8

El tercer objetivo consiste en "desarrollar políticas integrales de población y migración, que contribuyan a la inclusión, la prosperidad y el ejercicio de derechos" con el fin concreto de "consolidar una gestión migratoria eficaz, fundamentada en criterios de facilitación, corresponsabilidad internacional, seguridad fronteriza y seguridad humana". ${ }^{9}$

En cuarto lugar, se proponen programas sectoriales de salud, educación y trabajo para "cerrar las brechas existentes en salud entre diferentes grupos sociales y regiones del país" para "favorecer los procesos de integración y reintegración de los migrantes y sus familias". ${ }^{10}$

Finalmente, el quinto objetivo tiene que ver con los programas sectoriales de Relaciones Exteriores, Procuración de Justicia y de Desarrollo Agrario Territorial y Urbano, con el propósito de "fortalecer el acceso a la justicia y seguridad de las personas migrantes, familiares y quienes defienden sus derechos". 11

Sin duda, el Programa Especial de Migración, tal como se publicó en el Diario Oficial de la Federación, ofrece un marco de acción gubernamental bien delineado, con objetivos claros y estrategias y líneas de acción específicas. Va mucho más allá de una declaración de principios y responsabiliza a un conjunto de secretarías y dependencias. No obstante, su aplicación dejó mucho que desear, en buena parte debido a los encargados de llevarla a cabo.

${ }^{7}$ Loc. cit.

${ }^{8}$ Loc. cit.

${ }^{9}$ Loc. cit.

${ }^{10}$ Loc. cit.

${ }^{11}$ Loc. cit. 


\section{LOS OPERADORES POLÍTICOS}

La coordinación del Programa Especial de Migración recayó en la Secretaría de Gobernación (SEGOb), su Subsecretaría de Población, Migración y Asuntos Religiosos, la Unidad de Política Migratoria y un conjunto de otras dependencias, dado que se planteó como una política intersectorial e intersecretarial. Y es en ese terreno, el de los funcionarios y personas encargadas de llevar a cabo los lineamientos del Programa Especial de Migración, en donde la orientación, interés y voluntad política de la administración de Peña Nieto dejó mucho que desear.

En un primer periodo (del 5 de diciembre de 2012 al 11 de enero de 2015), la Subsecretaría de Población, Migración y Asuntos Religiosos de la SEGOB estuvo a cargo de María del Carmen Guillén Vicente, con experiencia en cargos gubernamentales en Tamaulipas y como diputada local del Partido Revolucionario Institucional (PRI). Luego, el cargo estuvo vacante durante nueve meses, hasta que se nombró a Humberto Roque Villanueva, conocido operador político del PRI, quien lo ocupó del 10 de septiembre de 2017 al 10 de enero de 2018. Finalmente, con la salida del secretario de Gobernación, Miguel Ángel Osorio Chong, y su sustitución por Alfonso Navarrete Prida, éste puso al frente de la subsecretaría a Patricia Martínez Cranss, quien formaba parte de su equipo. En los tres casos, las designaciones en esta subsecretaría respondieron a reacomodos de tipo político, más que al ánimo de contar con personas o funcionarios que, de una u otra manera, hubieran estado involucrados profesionalmente en el tema o que conocieran medianamente la problemática.

Por el contrario, en el caso del comisionado del Instituto Nacional de Migración (INAMI), encargado de la operación política y ejecutoria con respecto a inmigración, tránsito y retorno, la designación recayó en Ardelio Vargas Fosado, con un amplio currículo en temas y cargos de seguridad nacional (Centro de Investigación y Seguridad Nacional, Secretaría de Seguridad Pública y Policía Federal Preventiva) y con 
un historial que lo compromete en los casos de graves de violaciones a los derechos humanos en Atenco, Estado de México, y contra la Asamblea Popular de los Pueblos de Oaxaca (APPo). Durante los cinco años que se mantuvo en el cargo, su gestión se caracterizó por la opacidad y una política enfocada desde los principios de la seguridad nacional. Sin duda, se distinguió por la deportación de migrantes en tránsito y el "aseguramiento" de menores migrantes centroamericanos (9630 en 2013, 23096 en 2014, 38514 en 2015 y 40542 en 2016), según datos de la Unidad de Política Migratoria.

En este periodo se hicieron diversas denuncias contra el INAMI, como la de contratar a empresas privadas para detener a migrantes, ${ }^{12}$ de corrupción y de abuso de las personas migrantes. ${ }^{13}$ Las quejas de extranjeros llegaron a tal límite, que el Senado tuvo que precisar que el INAMI no tiene facultades ministeriales, ni policiacas. ${ }^{14}$ Con el cambio de 2017 en la SEGOB, Ardelio Vargas fue reemplazado por Gerardo Elías García Benavente, también con experiencia previa en la Agencia de Seguridad Estatal del Estado de México.

El contraste entre los planteamientos, estrategias, líneas de acción y buenos propósitos del Programa Especial de Migración resulta patético al analizar la designación de funcionarios públicos con un perfil muy poco adecuado para una subsecretaría encargada de los temas de población y migración, y se vuelve preocupante con la designación de operado-

12 Ricardo Raphael, "INM contrata privados para violar derechos", El Universal, 6 de noviembre de 2017, http://www.eluniversal.com.mx/ columna/ricardo-raphael/nacion/inm-contrata-privados-para-violarderechos

${ }^{13}$ Gloria Leticia Díaz, "En migración, podredumbre extrema", Proceso, 31 de agosto de 2013, https://www.proceso.com.mx/351542/en-mi gracion-podredumbre-extrema

${ }^{14}$ Senado de la República - Coordinación de Comunicación Social, "Senado precisa facultades del INM en materia de denuncias contra extranjeros", 30 de marzo de 2017, http://comunicacion.senado.gob.mx/ index.php/informacion/boletines/35513-senado-precisa-facultades-delinm-en-materia-de-denuncias-contra-extranjeros.html 
res políticos de corte policiaco en el INAMI, que es responsable del trato directo con la población migrante.

De manera concomitante a la SEGOB, la SRE tiene a su cargo la política exterior y la atención y protección de mexicanos residentes en el exterior, muy especialmente en Estados Unidos, donde se dispone de cincuenta consulados y se concentran 11.5 millones de migrantes, la mitad de los cuales están en situación irregular y, por tanto, vulnerable.

Visto desde el lado de la política exterior y la migración, el sexenio podría dividirse en dos partes: antes y después de la visita de Trump el 31 de agosto de 2016. Pero desde el punto de vista de los funcionarios de primer nivel a cargo de la cancillería, que llevan a cabo la política migratoria, propiamente son tres los periodos en los que pueden distinguirse modos personales y políticas adecuadas a cada coyuntura.

El periodo de José Antonio Meade (del $1^{\circ}$ de diciembre de 2018 al 26 de agosto de 2015) se podría calificar como de "distensión" en las relaciones bilaterales, de una política "sin estridencias” y de no intervención. Incluso, desde la cancillería, se abstuvieron de intervenir y opinar cuando se discutía y se aprobó en el Senado de Estados Unidos una reforma migratoria integral y bipartidista que hubiera cambiado el destino de varios millones de mexicanos. Esta postura, acorde con la asesoría de expertos y consejeros estadounidenses, era contraria a lo que opinaban y sugerían las organizaciones de mexicanos en aquel país.

Más allá de las oportunidades de incidir en la política del vecino del norte, la marea cambió de rumbo y Estados Unidos presionó a México para que interviniera en la crisis de familias y menores migrantes centroamericanos y frenara su tránsito por territorio mexicano. La crisis fue definida por el presidente Obama como una crisis humanitaria.

La respuesta mexicana fue la creación del programa Frontera Sur, que proponía como objetivos prioritarios el paso formal y ordenado, el ordenamiento fronterizo y mayor seguridad para los migrantes; la protección y acción social a favor de los migrantes, y la corresponsabilidad regional y la coordinación 
interinstitucional. ${ }^{15}$ En teoría, un programa acorde, en buena medida, con las intenciones y propuestas del Programa Especial de Migración.

Por otra parte, se propuso el trabajo conjunto de México y Guatemala para hacer de la frontera una zona más segura, inclusiva y competitiva. Si bien los menores guatemaltecos eran los que emigraban en mayores cantidades, también era importante el flujo de salvadoreños y hondureños. El 12 de julio de 2014, desde Chiapas, Peña Nieto propuso de manera conjunta con el presidente de Guatemala, Otto Pérez Molina, la puesta en marcha del programa, en el entendido de que el fenómeno migratorio debe ser atendido desde una perspectiva regional, corresponsable y humana.

En la práctica, el Programa Frontera Sur no tuvo apoyo ni presupuesto; fue más bien el INAMI, con su política de seguridad nacional, el que se encargó de desplegar la barrera de contención y deportación sistemática. Las cifras de detenciones de menores en tránsito por México fueron significativamente mayores a las que se reportaron en Estados Unidos. Nuevamente, el accionar de los funcionarios desplegados en el campo por el inAmi fue ampliamente criticado, con denuncias de corrupción, violaciones a los derechos humanos y condiciones inapropiadas de detención de menores. ${ }^{16}$

Según Erick Olson, del Wilson Center, hubo "una influencia obvia" de Estados Unidos en el lanzamiento del Programa Frontera Sur en México, aunque recalca que esta iniciativa no es el primer intento de implementar una coordinación integral en la frontera mexicana con Guatemala”. De hecho, el tema está planteado desde 2001 como prioritario en

${ }^{15}$ Christopher Wilson y Pedro Valenzuela, México's southern border strategy: Programa Frontera Sur, Washington, DC, Wilson Center, Mexico Institute, 11 de julio de 2014, p. 2.

${ }^{16}$ Alejandra Castañeda, “¿Qué es el Programa Frontera Sur?”, en Observatorio de legislación y política migratoria, Boletín núm. 1 (febrero de 2016), http://observatoriocolef.org/wp-content/uploads/2016/06/BO LET\%C3\%8DN-1-Alejandra-Casta\%C3\%B1eda.pdf 
el Plan Puebla-Panamá, articulado con el Sistema de la Integración Centroamericana. ${ }^{17}$

Otro rubro poco claro de este periodo es el financiamiento por parte de la SRE de la asociación Juntos Podemos, dirigida por Josefina Vásquez Mota, excandidata panista a la presidencia de la República en 2012. De manera poco transparente y al parecer por criterios o favores políticos, se destinaron cerca de 900 millones de pesos, que provenían originalmente de fondos del IME. Esta asociación, encabezada por un supuesto competidor político, recibía los fondos destinados a distintas actividades que realizaban los consulados con la comunidad mexicana radicada en Estados Unidos.

Dichos fondos se depositaron, entre 2014 y 2016, a la Asociación de Empresarios Mexicanos, mediante sus filiales AEM uSA Foundation y Parents Alliance Inc., que estaban facultadas para recibir donativos y que, a su vez, los transferían a los programas dirigidos por Vázquez Mota y el director ejecutivo de Juntos Podemos, Jorge Santibáñez, radicados en Dallas, Texas. ${ }^{18}$

Lo más curioso de todo es que Vázquez Mota regresó a la política en 2017, como candidata del Partido Acción Nacional (PAN) a la gubernatura del Estado de México. Según las estimaciones de la época tenía, muy pocas posibilidades de ganar, dado los resultados que había logrado en 2012, pero se le consideraba como una buena alternativa para fraccionar el voto, que finalmente le dio el triunfo, por enésima vez

17 Manu Ureste, "Programa Frontera Sur: el discurso de derechos humanos con el que México 'caza' a miles de migrantes", Animal Político, 28 de abril de 2015, https://www.animalpolitico.com/2015/04/programa-frontera-sur-el-discurso-de-derechos-humanos-con-el-que-mexico-caza-a-miles-de-migrantes/

18 Salvador Camarena y Dulce González (2016), "Juntos Podemos, que preside Josefina Vázquez Mota, ha recibido 900 mdp del gobierno de Peña", Animal Político, 4 de octubre de 2016, https://www.animalpolitico. com/2016/10/juntos-podemos-vazquez-mota-recursos / 
consecutiva, al PRI sobre su más cercano competidor, el Movimiento de Regeneración Nacional (MORENA). ${ }^{19}$

Posteriormente, la Auditoría Superior de la Federación (ASF) notificó la existencia de irregularidades en la entrega de recursos públicos, de 2014 a 2016, a la organización Juntos Podemos, que actuaba a través de los consulados en Estados Unidos, con fondos que supuestamente eran de ellos (específicamente del Instituto de los Mexicanos en el Exterior, IME), pero que eran administrados por otros, en este caso, la fundación mencionada. La ASF determinó daños probables por unos 39 millones de pesos y promovió 34 recomendaciones y 18 denuncias por irregularidades que originalmente habían sido denunciadas por el grupo Mexicanos Unidos contra la Corrupción y la Impunidad. ${ }^{20}$

De manera un poco sorpresiva, José Antonio Meade dejó la SRE y fue reemplazado por Claudia Ruiz Massieu, con experiencia en el Congreso y como secretaria de Turismo. Su periodo, del 27 de agosto de 2015 al 4 de enero de 2017 , puede calificarse como gris, precisamente en uno de los momentos más álgidos de la relación bilateral con Estados Unidos, cuando Trump ya había iniciado su campaña para las elecciones primarias, el 16 de junio de 2015, y definía como eje de su discurso la lucha frontal contra la inmigración "ilegal" y la importancia de construir un muro en la frontera como única salida para frenar la migración y las drogas. $\mathrm{Su}$ lema de campaña "Make America Great Again" auguraba un cambio radical hacia la derecha.

La lectura del escenario político estadounidense para las primarias y la carrera por la presidencia no vaticinaba a Trump en la recta final. Quizá el único que le vio algún futuro fue el secretario de Hacienda y Crédito Público, Luis Vi-

${ }^{19}$ Josefina Saldierna, "El Pan ve difícil el triunfo de Vázquez Mota en el Estado de México", La Jornada, 31 de mayo de 2017, https://www.jornada.com.mx/2017/05/31/politica/003n1pol

20 "La ASF confirma irregularidades en la entrega de recursos a Juntos Podemos por 39.4 mdp", Proceso, 22 de noviembre de 2017, https://www. proceso.com.mx/512117/la-asf-confirma-irregularidades- 
degaray. Por eso, promovió la visita de Trump, a fines de agosto de 2016, de manera directa con el presidente Peña Nieto y al parecer sin contar con la anuencia de la canciller. La excusa no pedida fue la siguiente: "La conducción de la política exterior corresponde a la Secretaría de Relaciones Exteriores y todas las secretarías de Estado, incluyendo la SHCP, tienen coordinación plena con la cancillería”. ${ }^{21}$

La visita fue mal preparada y peor aún el discurso del presidente, que no planteó de manera pública y directa su posición con respecto al muro y a la exigencia de que México debía pagarlo. Por su parte, Trump, horas después en un mitin de campaña en Phoenix, Arizona, volvió a arremeter contra México y los migrantes mexicanos. Tema que no dejaría de lado en ningún momento, ni como candidato ni como presidente.

El 27 de agosto de 2016, la SRE emitió un comunicado de prensa que dice: "Como ha sostenido siempre el gobierno de México, nuestro país no pagará, de ninguna manera y bajo ninguna circunstancia, un muro o barrera física que se construya en territorio estadounidense a lo largo de la frontera con México. Está determinación no es parte de una estrategia negociadora, sino un principio de soberanía y dignidad nacional". ${ }^{22}$

Las consecuencias fueron desastrosas para el secretario Luis Videgaray, quien aceptó que "la visita de Trump a México tuvo consecuencias dolorosas y graves; me hago responsable". Pero el ajedrez político lo llevaría meses después a la propia cancillería y con Trump en la presidencia. Entonces, pudo darse el lujo de afirmar ante el Senado de la República:

se debe reconocer que el haber establecido una relación con quien a la postre resultó ser presidente de Estados Unidos, y

21 “¿Quién fue el de la idea de invitar a Trump a México? (foto)", Mundo Hispánico, [s/f], https://mundohispanico.com/noticias/naciona les / quien-fue-el-de-la-idea-de-invitar-a-trump-a-mexico

${ }^{22}$ Loc. cit. 
con su equipo de trabajo, generó condiciones de interlocución que sólo México tiene, comparado con otras naciones en el mundo. ${ }^{23}$

Por otra parte, una de las demandas más sentidas de la comunidad mexicana radicada en el exterior era la posibilidad de obtener la credencial del INE, que en la práctica opera como un documento o cédula nacional de identidad, aunque no sea obligatoria ni universal. Es, sin embargo, el único documento que permite votar en las elecciones y, además, sirve como identificación en el país y en el extranjero.

Más allá del hecho formal de tramitar este documento y de su utilidad práctica, la credencial del INE establece un vínculo directo, identitario, con el país de origen. Pero esta posibilidad les había sido negada a los 12 millones de mexicanos radicados en el exterior. Es hasta diciembre de 2015 que finalmente se llega a un acuerdo entre el INE y la SRE para poder expedir dicha credencial en los consulados en todo el mundo. Algo que es práctica común y cotidiana en cualquier consulado, de cualquier país del mundo, fue una verdadera demanda social en contra de la exclusión en el caso de México.

Para paliar esta carencia, los consulados expedían "matrículas consulares" que servían de identificación a los mexicanos residentes en el exterior. Con estas matrículas podía enviarse dinero, en algunos casos tramitar la licencia de manejo, abrir cuentas en los bancos o identificarse ante la policía. Pero todo dependía de acuerdos que se hacían con cada país o autoridad local del extranjero. La mayoría de los migrantes en situación irregular necesitaba esta credencial para asuntos cotidianos relacionados con su residencia en otro país, incluso para poder comprar cerveza, pero la matrícula

23 Secretaría de Relaciones Exteriores, SRE, "Comunicado de prensa núm 326”, 27 de agosto de 2017, https://www.gob.mx/sre/prensa/comu nicado-de-prensa-123180 
no era válida para votar y tampoco servía como identificación oficial en México.

El futuro de la matrícula consular, que era sólo un paliativo, dependerá del tiempo y de las posibilidades que tengan los residentes en el exterior de obtener la credencial del INE. En los dos años que se expidieron en los consulados -en 2016, 2017 y unos meses de 2018-, se otorgaron cerca de 700000 credenciales. A esto hay que sumarle las credenciales vigentes que tenían migrantes residentes en el extranjero.

En las elecciones de 2018, se inscribió en la lista nominal a los mexicanos en el exterior con credencial para votar, lo que le otorgó finalmente derecho a sufragar a un total de 181873 residentes en el extranjero y, finalmente, enviaron su voto (en sobre postal) 98854 personas, desde 107 países diferentes.

Más allá del análisis electoral, lo que es interesante destacar es la gran diferencia entre el número de credenciales expedidas (700 000, sin contar las que estaban vigentes) y los votos válidos enviados, que son poco menos de 100000 . La inmensa distancia entre las dos cifras puede estar sujeta a varias interpretaciones, pero nos interesa destacar la más obvia: a los mexicanos residentes en el exterior les interesa tener la credencial del ine porque es válida como identificación en México y en el extranjero, aun cuando a final de cuentas no sea una cédula de identidad como tal. Sin embargo, sólo una porción de quienes la obtienen la utilizan para ejercer el derecho al voto. ${ }^{24}$

Políticas migratorias ReACtivas: LAS GARAVANAS DE 2018

El muro fronterizo y la criminalización de los migrantes continuó presente durante los últimos meses del sexenio de Peña Nieto, en los que también fue prioridad absoluta la renego-

24 "Elecciones 2018. Resultados del voto de los mexicanos residentes en el extranjero", Institituto Nacional Electoral, INE (sitio de internet), http:/ /www.votoextranjero.mx/web/vmre/elecciones2018 
ciación del Tratado de Libre Comercio. En ambas cuestiones, el gobierno optó por un perfil bajo ante las continuas agresiones de Trump contra los migrantes y un perfil proactivo en relación con las negociaciones comerciales.

Prácticamente, el único momento en que se perdió la compostura fue cuando Trump amenazó con enviar a la guardia nacional a la frontera el 3 abril de 2018, por la supuesta amenaza de la caravana Viacrucis del Migrante, que se organizaba desde Centroamérica. En este caso, la reacción en contra fue unánime y estridente, tanto en el Congreso, como entre los partidos, los candidatos, la prensa y la opinión pública. Peña Nieto llegó a decir, en medio de un largo discurso: "Los mexicanos podemos tener diferencias entre nosotros, y más aún en tiempos de elecciones, pero estaremos siempre unidos en la defensa de la dignidad y la soberanía de nuestro país [...] Si sus recientes declaraciones derivan de una frustración por asuntos de política interna, de sus leyes o de su Congreso, diríjase a ellos, no a los mexicanos. No vamos a permitir que la retórica negativa defina nuestras acciones". 25

No obstante, el manejo político de esta caravana tendría repercusiones inesperadas meses después. En un comunicado de las secretarías de Gobernación y Relaciones Exteriores se afirma, de manera un poco apresurada, que "como se esperaba, la caravana conocida como 'Viacrucis del Migrante' comenzó su dispersión por decisión de sus integrantes". Y luego se explican las medidas tomadas:

Con relación a los extranjeros que conformaban la caravana migrante, el gobierno de México ha centrado sus esfuerzos en informar sobre los procesos de regularización y opciones previstas en la Ley de Migración; asimismo, se han iniciado los

25 Transcripción del Mensaje a la Nación, 6 de abril de 2018. Véase: Rolando Ramos, "Nadie está por encima de la dignidad de México: Peña", El Economista, 5 de abril de 2018, https:/ /www.eleconomista.com.mx/po litica/Nadie-esta-por-encima-de-la-dignidad-de-Mexico-Pena-2018 0405-0 175.html 
procedimientos administrativos migratorios a quienes manifestaron dicho interés (465 personas solicitaron oficios de salida, de los cuales 230 han sido entregados). Además, 168 de ellos se encuentran en los supuestos de ley para recibir esta misma notificación con fines de regularización, que serán otorgados en las próximas horas. ${ }^{26}$

En realidad, la ley no estipula propiamente los "permisos de salida" que, en la práctica, no son otra cosa que visas de tránsito de veinte días para dejar el país por alguna de sus fronteras, entiéndase la de Estados Unidos. De hecho, poco más de 400 miembros de esa caravana solicitaron refugio en el vecino país. Los permisos de tránsito propiamente requieren la visa del país de destino.

Sin embargo, ésta era una práctica utilizada en algunos casos, como el de los cubanos, que tenían el refugio prácticamente asegurado en Estados Unidos, hasta que se canceló esta posibilidad al final del gobierno de Obama y, en el de los haitianos y africanos que llegaron masivamente a Tijuana a mediados de 2016 y estaban bajo la protección de la Agencia de la ONU para los Refugiados (ACNUR). No se solía dar "permiso de salida" a los centroamericanos; de hecho, la política que se aplicaba era la deportación, salvo que se solicitara expresamente refugio en México. ${ }^{27}$

$\mathrm{Al}$ parecer, esta medida enfureció al gobierno de Trump, que lidiaba con la llegada masiva de familias y menores de edad solicitando refugio. De hecho, la caravana Viacrucis del Migrante transitó por México en abril y en julio se desató la crisis de la separación de familias. Pero desde sus primeras órdenes ejecutivas sobre la frontera y la seguridad interior, el gobierno de Trump señaló que había que terminar con las

${ }^{26}$ Secretaría de Relaciones Exteriores, SRE, "La política migratoria no está sujeta a presiones: Gobierno de México", 3 de abril de 2018, https://www.gob.mx/sre/prensa/politica-migratoria-no-esta-sujeta-a-pre siones-gobierno-de-mexico

27 Jorge Durand, "Pasaporte infantil", La Jornada, 10 de junio de 2018, https://www.jornada.com.mx/2018/06/10/opinion/015a2pol 
solicitudes de audiencia para refugio, por considerarlas "un abuso" y una forma de evadir la deportación inmediata. ${ }^{28}$

De hecho, la negociación para obtener los "permisos de salida”, en el caso de la caravana Viacrucis del Migrante, la llevaron a cabo los líderes de la organización Pueblos sin Fronteras, entre ellos, el mexicano-estadounidense Irineo Mújica, organizador de varias de estas expediciones. Según el comunicado de la SRE, este tipo de caravanas se viene realizando anualmente desde 2010 y se intensificaron después de la creación del plan Frontera Sur, que limita el acceso a "La Bestia", como se conoce a la red de trenes de carga que utilizan los migrantes indocumentados para transportarse desde la frontera sur de México hasta Estados Unidos.

No hay información pública sobre la reacción del gobierno estadounidense ante la actitud de México de otorgar "permisos de salida". Lo que sí puede constatarse es que unos meses después, en octubre de 2018, en plena campaña por las elecciones intermedias en Estados Unidos y en pleno proceso de cambio de gobierno en México, se inicia de manera súbita y con fuerza el éxodo hondureño. Ante esto, la política migratoria mexicana da un giro radical en cuanto a su postura formal y se acomoda como puede a una coyuntura totalmente nueva e inesperada.

El 12 de octubre, en San Pedro Sula, Honduras, por medio de las redes sociales y un debate televisivo con el líder social y exdiputado opositor Bartolo Fuentes, que opera como detonador, surge una caravana migrante como forma de protesta social contra el régimen de Juan Orlando Hernández. Hay un caldo de cultivo explosivo formado por múltiples factores: pobreza extrema, trabajo precario, violencia endémica y sistémica, impunidad institucional, fraude electoral y desencanto generalizado. En cuestión de horas, el día 13 de octu-

28 Donald J. Trump, "Executive Order: Enhancing Public Safety in the Interior of the United States", The White House (sitio de internet de la Casa Blanca), 25 de enero de 2017, https://www.whitehouse.gov/pre sidential-actions/executive-order-enhancing-public-safety-interior-uni ted-states/ 
bre, se ponen en marcha 1500 personas, hombres, mujeres, familias, niños, y en el camino se les suman cientos, miles. ${ }^{29}$

El gobierno de Honduras emitió un comunicado donde afirma que la caravana tenía motivaciones políticas: "Solicitamos a los diversos sectores políticos del país no usar a los hondureños como bandera de lucha política para sus propios intereses, ya que de por medio está la seguridad y la vida de decenas de hondureños que tienen un anhelo legítimo de que sus condiciones de vida mejoren". El vicepresidente de Estados Unidos, Mike Pence, se hizo eco de la postura hondureña y afirmó a The Washington Post lo siguiente: "El presidente de Honduras me dijo que la caravana es organizada por grupos izquierdistas en Honduras financiados por Venezuela y enviados al norte para desafiar nuestra soberanía y desafiar nuestra frontera". 30

Por su parte, el gobierno de México fijó su posición mediante un comunicado conjunto de la Segob y la SRE en el que se precisan tres puntos:

Primero. Toda persona que desee ingresar a territorio nacional y cuente con los documentos de viaje y una visa concedida por el gobierno de México, por medio de la red consular de la Secretaría de Relaciones Exteriores, podrá ingresar al país y moverse con plena libertad en el mismo por el tiempo de vigencia de la visa.

Segundo. Toda persona que ingrese a territorio nacional y desee solicitar el reconocimiento de la condición de refugiado o ser beneficiario de medidas de protección complementaria, deberá hacerlo individualmente, de conformidad con la legislación vigente $[\ldots]$.

29 "Cronología de la caravana centroamericana”, México, El Colegio de la Frontera Norte (sitio de internet), 9 de noviembre de 2018, http:/ / observatoriocolef.org/infograficos/cronologia-de-la-caravana-centroa mericana/

30 "Gobierno de la República de Honduras. Comunicado", Tegucigalpa, 16 de octubre de 2018, http://www.sre.gob.hn/portada/2018/Octu bre/16-10-18/COMUNICADO\%20SRECI\%201.pdf 
Tercero. En cumplimiento de la legislación nacional vigente, toda persona que ingrese al país de manera irregular, será rescatada y sujeta a procedimiento administrativo y, en su caso, será retornada a su país de origen, de manera segura y ordenada $[\ldots] .{ }^{31}$

El 17 de octubre, la caravana llega a la frontera con México y se agolpa en el puente. Se ha convertido en un éxodo de 4000 personas, de características inéditas: masivo, multinacional, mediático, frontal, exigente, demandante. Al día siguiente, la presión de la marea humana rompe el cerco e ingresa a México. El mundo entero está atento al suceso y lo sigue día a día. El 7 de noviembre, la caravana arriba a la Ciudad de México y el 8, cientos de sus integrantes marchan a las oficinas de la Organización Internacional para las Migraciones (OIM) con el fin de exigir transporte a la frontera norte, lo que les es negado. El 14 de noviembre empiezan a llegar, por su cuenta, miles de migrantes a Tijuana.

La crisis migratoria y mediática obligó a Peña Nieto a tratar el tema y plantear su política en dos ocasiones en cadena nacional. En su primera intervención ofreció que "toda persona que ingresara a nuestro país podría solicitar de manera individual el reconocimiento como refugiado". ${ }^{32}$ En la segunda, el 26 de octubre, vuelve a intentar frenar la caravana con un ofrecimiento y un programa específico llamado Estás en tu Casa:

Estando en México, podrás recibir atención médica e incluso, mandar a tus hijos a la escuela; también tendrás una identifi-

${ }^{31}$ Secretaría de Relaciones Exteriores, SRE, "Medidas del gobierno de México ante la eventual llegada a la frontera sur de la caravana de migrantes hondureños", comunicado conjunto sRE-Segob, 17 de octubre de 2018, https://www.gob.mx/sre/prensa/medidas-del-gobierno-de-mexico-antela-eventual-llegada-a-la-frontera-sur-de-la-caravana-de-migrantes-hondure nos?state=published

${ }^{32}$ Presidencia de la República, "Mensaje del Presidente Enrique Peña Nieto" (comunicado televisado, archivo de video), YouTube, 19 de octubre de 2018, https://www.youtube.com/watch?v=R4I5ehgvylc 
cación oficial temporal para hacer los trámites que necesites mientras regularizas tu situación migratoria. Además, ese documento te permitirá entrar y salir de los albergues de Oaxaca o Chiapas cuando quieras. Y algo muy importante: $\mathrm{Al}$ incorporarte al plan, podrás acceder al Programa de Empleo Temporal. ${ }^{33}$

El cambio fundamental entre la caravana Viacrucis del Migrante y la de octubre fue su dimensión, su impacto mediático y la fuerza arrolladora de una masa de humanidad desgarrada y vulnerable. Parecía animada por una fuerza y voluntad imparables hasta que llegaron al muro fronterizo en Tijuana y se toparon con una política migratoria de tolerancia cero. $\mathrm{O}$ casi cero, porque todavía existen pequeñas rendijas legales, o informales, que permiten el ingreso. En cuanto a la política migratoria, el cambio fundamental fue que ya no se otorga ningún "permiso de salida”, una medida pragmática que posiblemente quede envuelta en la opacidad y que la historia tendrá que develar.

No obstante los cambios, adecuaciones, comunicados e improvisaciones, México ha mantenido una posición firme en cuanto a las pretensiones de Estados Unidos de firmar un pacto como "tercer país seguro" y ha manifestado y repetido que "la política migratoria de nuestro país se define de manera soberana, con base en nuestros principios y atendiendo al interés nacional de México" y que "la caravana migrante proveniente de Centroamérica es un fenómeno humanitario inédito, que requiere del trabajo conjunto de todos los países de la región". ${ }^{44}$

${ }^{33}$ Presidencia de la República, "Plan estás en tu casa", (comunicado televisado del presidente Enrique Peña Nieto, archivo de video), YouTube,26deoctubrede2018,https:/ / www.youtube.com/watch?v=pxyfBfu5I_w

${ }^{34}$ Secretaría de Relaciones Exteriores, SRE,"Posicionamiento ante la proclama presidencial estadounidense para limitar la posibilidad de solicitar asilo desde la frontera con México", Comunicado núm. 305, 10 de noviembre de 2018, https://www.gob.mx/sre/prensa/posicionamientoante-la-proclama-presidencial-estadounidense-para-limitar-la-posibilidadde-solicitar-asilo-desde-la-frontera-con-mexico?idiom=es 


\section{Conclusiones}

La política migratoria se tiene que ajustar a las coyunturas, eso es inevitable, pero debe mantener una base de principios fundamentales de acuerdo con la ley y en concordancia con la historia y el presente de México como tierra de origen, tránsito, destino y retorno de migrantes. Ahora, también habría que incluir el refugio como una condición no excepcional, sino permanente, ante las crisis humanitarias del subcontinente americano, como la de este éxodo masivo hondureño y centroamericano.

El Pacto Mundial para la Migración Segura, Ordenada y Regular, del que México fue auspiciador (como lo muestra la reunión preparatoria realizada en Puerto Vallarta en diciembre de 2017) y que se firmó en Marrakech, Marruecos, en diciembre de 2018, exige la aplicación de un principio básico, ya estipulado en múltiples foros internacionales: el de la "responsabilidad compartida". Un principio que obviamente no tiene un correlato empírico, ni en los países centroamericanos de origen ni menos aún en el de destino, Estados Unidos, cuyo gobierno, por lo pronto, ya se retiró formalmente de este pacto. ${ }^{35}$

En el caso de la crisis política, humanitaria y migratoria del éxodo hondureño y centroamericano, no puede eludirse la responsabilidad directa de Estados Unidos en su área de influencia y control político regional. La crisis recurrente de Centroamérica, después ser el último escenario sangriento de la Guerra Fría en los ochenta, evidencia el fracaso del modelo económico y la debilidad institucional de sus gobiernos "democráticos" plagados de impunidad y corrupción. En ese contexto, la migración se sigue manifestando como la tradicional "válvula de escape" ante la presión que

35 "Naciones Unidas. Asamblea General. Conferencia Intergubernamental encargada de Aprobar el Pacto Mundial para la Migración Segura, Ordenada y Regular", 30 de julio de 2018, http://undocs.org/es/A/ CONF.231/3 
ejerce la crisis humanitaria y de violencia social y económica en la región.

Por otra parte, el otro principio básico de Naciones Unidas y del Pacto Mundial es el de "coherencia institucional", que, en otras palabras, significa ser equitativo entre lo que se exige y lo que se practica. En el caso de México, este principio fue puesto a prueba con las caravanas de 2018 y. salvo diversos errores y omisiones de nivel federal, estatal y municipal, se trató de salvaguardar los derechos humanos de los migrantes y de solventar la crisis coyuntural que supone recibir de manera masiva a cerca de una decena de miles de migrantes en tránsito hasta la frontera. No obstante esto requiere de mayor información y distancia temporal para poder ser evaluado.

\section{REFERENCIAS BIBLIOGRÁFICAS}

Camarena, Salvador y Dulce GonzÁlez, "Juntos Podemos, que preside Josefina Vázquez Mota, ha recibido 900 mdp del gobierno de Peña”, Animal Político, 4 de octubre de 2016, https:/ /www.animalpolitico.com/2016/10/juntos-podemosvazquez-mota-recursos/

Castañeda, Alejandra, “¿Qué es el Programa Frontera Sur?”, en Observatorio de legislación y política migratoria, Boletín núm. 1, (febrero de 2016), http:/ /observatoriocolef.org/wp-content/upl oads/2016/06/BOLET\%C3\%8DN-1-Alejandra-Casta \%C3\% Bleda.pdf

Castañeda, Jorge G., Ex mex: From migrants to immigrants, Nueva York/Londres, The New Press, 2009.

"Cronología de la caravana centroamericana", El Colegio de la Frontera Norte (sitio de internet) 19 de noviembre de 2018, http:/ / observatoriocolef.org/infograficos/cronologia-de-lacaravana-centroamericana/

Decreto por el que se expide la Ley de Migración y se reforman, derogan y adicionan diversas disposiciones de la Ley General de Población, del Código Penal Federal, del Código Federal de 
Procedimientos Penales, de la Ley Federal contra la Delincuencia Organizada, de la Ley de la Policía Federal, de la Ley de Asociaciones Religiosas y Culto Público, de la Ley de Inversión Extranjera, y de la Ley General de Turismo, Diario Oficial de la Federación, 25 de mayo de 2011, http://www.diputados.gob. $\mathrm{mx} /$ LeyesBiblio/ref/lmigra/LMigra_orig_25may11.pdf

Díaz, Gloria Leticia, "En migración, podredumbre extrema", Proceso,31 de agosto de 2013, https:/ / www.proceso.com.mx/351542/ en-migracion-podredumbre-extrema

DuRAnD, Jorge, “La ‘desmigratización’ de la relación bilateral: balance del sexenio de Felipe Calderón”, Foro Internacional, 53 (2013), pp. 750-770.

Durand, Jorge, "Pasaporte infantil", La Jornada, 10 de junio de 2018, https://www.jornada.com.mx/2018/06/10/opinion/01 $5 \mathrm{a} 2 \mathrm{pol}$

"Elecciones 2018. Resultados del voto de los mexicanos residentes en el extranjero", Instituto Nacional Electoral, INE (sitio de internet), http://www.votoextranjero.mx/web/vmre/elecciones2018

Executive Order: Enhancing Public Safety in the Interior of the United States, 25 de enero de 2017, Washington, DC, The White House (sitio de internet), https://www.whitehouse.gov/presi dential-actions/executive-order-enhancing-public-safety-inte rior-united-states/

"Gobierno de la República de Honduras. Comunicado", 16 de octubre de 2018, http://www.sre.gob.hn/portada/2018/Octubre/16-10-18/COMUNICADO\%20SRECI\%201.pdf

"La ASF confirma irregularidades en la entrega de recursos a Juntos Podemos por 39.4 mdp", Proceso, 22 de noviembre de 2017, https:/ / www.proceso.com.mx/512117/la-asf-confirma-irregularidades-

"Naciones Unidas. Asamblea General. Conferencia Intergubernamental encargada de Aprobar el Pacto Mundial para la Migración Segura, Ordenada y Regular", 30 de julio de 2018, http:/ / undocs.org/es/A/CONF.231/3

Presidencia de la República, "Mensaje del Presidente Enrique Peña Nieto" (comunicado televisado, archivo de video), YouTube, 
19 de octubre de 2018, https://www.youtube.com/watch?v=R4 I5ehgvylc

Presidencia de la República, "Plan estás en tu casa" (comunicado televisado del presidente Enrique Peña Nieto, archivo de video), YouTube, 26 de octubre de 2018, https://www.youtube. com/watch?v=pxyfBfu5I_w

Programa Especial de Migración, Diario Oficial de la Federación, 30 de abril de 2104.

“¿Quién fue el de la idea de invitar a Trump a México? (foto)", Mundo Hispánico, (s/f), https://mundohispanico.com/noticias / nacionales / quien-fue-el-de-la-idea-de-invitar-a-trump-amexico

Ramos, Rolando, "Nadie está por encima de la dignidad de México: Peña", El Economista, 5 de abril de 2018, https:/ / www.eleconomista.com.mx/politica/Nadie-esta-por-encima-de-la-dig nidad-de-Mexico-Pena-20180405-0175.html

RAPHAEL, Ricardo, "INM contrata privados para violar derechos", El Universal, 6 de noviembre de 2017, http://www.eluniversal. com.mx/columna/ricardo-raphael/nacion/inm-contrata-privados-para-violar-derechos

Saldierna, Josefina, "El pan ve difícil el triunfo de Vázquez Mota en el Estado de México", La Jornada, 31 de mayo de 2017, https://www.jornada.com.mx/2017/05/31/politica/003 n1pol

Secretaría de Relaciones Exteriores, sRe, "Comunicado de prensa núm. 326”, 27 de agosto de 2017, https://www.gob.mx/sre/ prensa/comunicado-de-prensa-123180

Secretaría de Relaciones Exteriores, SRE, "Medidas del gobierno de México ante la eventual llegada a la frontera sur de la caravana de migrantes hondureños", Comunicado conjunto SRE-Segob, 17 de octubre de 2018, https://www.gob.mx/sre/prensa/medidas-del-gobierno-de-mexico-ante-la-eventual-llegada-a-lafrontera-sur-de-la-caravana-de-migrantes-hondurenos?state= published

Secretaría de Relaciones Exteriores, SRE, "La política migratoria no está sujeta a presiones: gobierno de México", 3 de abril de 
2018, https://www.gob.mx/sre/prensa/politica-migratoria-noesta-sujeta-a-presiones-gobierno-de-mexico

Secretaría de Relaciones Exteriores, SRE, "Posicionamiento ante la proclama presidencial estadounidense para limitar la posibilidad de solicitar asilo desde la frontera con México", https:/ / www.gob.mx/sre/prensa/posicionamiento-ante-la-proclamapresidencial-estadounidense-para-limitar-la-posibilidad-de-so licitar-asilo-desde-la-frontera-con-mexico?idiom=es

Senado de la República - Coordinación de Comunicación Social, "Senado precisa facultades del INM en materia de denuncias contra extranjeros", 30 de marzo de 2017, http:/ / comunicacion.senado.gob.mx/index.php/informacion/boletines/3551 3-senado-precisa-facultades-del-inm-en-materia-de-denunciascontra-extranjeros.html

Ureste, Manu, "Programa Frontera Sur: el discurso de derechos humanos con el que México 'caza' a miles de migrantes", Animal Político, https://www.animalpolitico.com/2015/04/progra ma-frontera-sur-el-discurso-de-derechos-humanos-con-el-quemexico-caza-a-miles-de-migrantes /

Wilson, Christopher y Pedro Valenzuela, México's southern border strategy: Programa Frontera Sur, Washington, DC, Wilson Center, Mexico Institute, 11 de julio de 2014. 
